\title{
Regulation of 2-Oxoglutarate Dehydrogenase Synthesis in Citrobacter freundii by Traces of Oxygen in Commercial Nitrogen Gas and by Glutamate
}

\author{
By C. W. KEEVIL, * J. S. HOUGH AND J. A. COLE \\ Department of Biochemistry, University of Birmingham, Birmingham B15 $2 T T$
}

(Received 12 April 1979)

\begin{abstract}
Glutamate induced the synthesis of 2-oxoglutarate dehydrogenase 50-fold during anaerobic growth of Citrobacter freundii and, in the absence of glutamate, this enzyme was even more active in cultures sparged with $\mathrm{N}_{2} / \mathrm{CO}_{2}(95: 5, \mathrm{v} / \mathrm{v})$. Enzyme synthesis was partially repressed when the inlet gas was passed through heated copper but totally repressed when the inlet gas was passed through alkaline pyrogallol and reduced benzyl viologen (a treatment which would remove $\mathrm{CO}_{2}$ as well as $\mathrm{O}_{2}$ ). Fumarate hydratase activity also decreased but alcohol dehydrogenase and the sum of the succinate dehydrogenase and fumarate reductase activities increased when residual $\mathrm{O}_{2}$ was removed from the sparging gas. Soluble cytochromes $a_{1}$ and $c_{552.5}$ were detected in rigorously anaerobic cultures. Thus traces of $\mathrm{O}_{2}$ which contaminate commercial compressed $\mathrm{N}_{2}$ are sufficient to induce 2-oxoglutarate dehydrogenase synthesis and to affect significantly the synthesis and incorporation of respiratory chain components into the cytoplasmic membrane.
\end{abstract}

\section{INTRODUCTION}

Previous studies in this laboratory were designed to investigate how $\mathrm{O}_{2}$ regulates catabolic pathways and respiratory enzyme synthesis in the facultatively anaerobic bacterium Citrobacter freundii (Keevil et al., 1977a, 1979). The observations that succinate dehydrogenase was the least active of the tricarboxylic acid cycle enzymes, that it was 12 times more active in bacteria from a glucose-limited than from a sulphate-limited continuous culture and that 2-oxoglutarate dehydrogenase activity varied little between aerobic and anaerobic cultures led us to conclude that the dominant mechanism for regulating tricarboxylic acid cycle activity was catabolite repression of succinate dehydrogenase synthesis rather than induction of 2-oxoglutarate dehydrogenase synthesis by $\mathrm{O}_{2}$. It was possible, however, that the small differences in 2-oxoglutarate dehydrogenase activity were due to enzyme induction during anaerobic growth either by glutamate, which was added as a growth supplement to the minimal medium, or by traces of $\mathrm{O}_{2}$ in the commercial $\mathrm{N}_{2}$ gas used to sparge the culture. The aims of the experiments described in this paper were therefore to determine whether the rate of synthesis of 2-oxoglutarate dehydrogenase is significantly affected by low concentrations of $\mathrm{O}_{2}$ or glutamate.

\section{METHODS}

Organism and media. Citrobacter freundii NCTC 9750 was maintained and grown in a 101 batch fermenter (L. H. Engineering Co., Stoke Poges, Bucks.) as described by Keevil et al. (1979). Unless otherwise stated, lysine, methionine, thiamin and glutamate were omitted from the minimal medium.

* Present address: Tate \& Lyle Group Research and Development, P.O. Box 68, Reading RG6 2BX. 
Table 1. Redox potential of the culture, molar growth yield and carbon balances of $C$. freundii grown anaerobically in a carbon-limited continuous fermenter

The percentage of glucose-carbon metabolized to volatile carbon products was calculated from the difference between the carbon concentration of the growth medium and the sum of the cell carbon and supernatant carbon concentrations. The glucose concentration in the feed medium was $30 \mathrm{~mm}$.

\begin{tabular}{|c|c|c|c|}
\hline & \multicolumn{3}{|c|}{ Inlet gas treatment } \\
\hline & None & $\begin{array}{l}\text { Heated } \\
\text { copper }\end{array}$ & $\begin{array}{l}\text { Alkaline } \\
\text { pyrogallol } \\
+\mathrm{BV}^{*}\end{array}$ \\
\hline $\begin{array}{l}\text { Redox potential (mV) } \\
\text { Glucose consumed (mM) } \\
\left.Y_{\text {glucose }}[\mathrm{g} \text { dry wt (mol glucose })^{-1}\right]\end{array}$ & $\begin{array}{l}-255 \\
30 \\
14 \cdot 4\end{array}$ & $\begin{array}{l}-262 \\
30 \\
14 \cdot 0\end{array}$ & $\begin{array}{l}-275 \\
30 \\
12 \cdot 1\end{array}$ \\
\hline $\begin{array}{l}\text { Carbon balance (\% C utilized) } \\
\text { Cell carbon } \\
\text { Soluble fermentation products } \\
\text { Volatile products }\end{array}$ & $\begin{array}{l}16 \cdot 2 \\
56 \cdot 4 \\
27 \cdot 4\end{array}$ & $\begin{array}{l}15 \cdot 7 \\
60 \cdot 9 \\
23 \cdot 4\end{array}$ & $\begin{array}{l}13 \cdot 6 \\
63 \cdot 9 \\
22 \cdot 5\end{array}$ \\
\hline
\end{tabular}

* BV, Reduced benzyl viologen.

Continuous culture experiments. The 51 fermentation vessel (L. H. Engineering Co.) contained 3.01 of unsupplemented minimal medium, $\mathrm{pH} 6.5$, at $37^{\circ} \mathrm{C}$. The dilution rate was $0.035 \mathrm{~h}^{-1}$. Steady states were established with cultures sparged at $100 \mathrm{ml} \mathrm{min}^{-1}$ with $\mathrm{N}_{2} / \mathrm{CO}_{2}(95: 5, \mathrm{v} / \mathrm{v})$ or $100 \% \mathrm{~N}_{2}($ British Oxygen Co., Wolverhampton); the gas was either (i) untreated or (ii) passed through a $1 \times 0.05 \mathrm{~m}$ Pyrex column packed with copper chippings heated to $340{ }^{\circ} \mathrm{C}$ (which would remove traces of $\mathrm{O}_{2}$ ) or (iii) passed through two $500 \mathrm{ml}$ wash bottles containing $300 \mathrm{ml} 20 \%$ (w/v) alkaline pyrogallol and a similar bottle containing $300 \mathrm{ml}$ $0.5 \%(\mathrm{w} / \mathrm{v})$ reduced benzyl viologen (Hempfling \& Mainzer, 1975) (which would remove both $\mathrm{O}_{2}$ and $\mathrm{CO}_{2}$ ). Part of the gas stream was used to sparge the feed medium: the remainder was passed into the fermenter either through silicone rubber tubing (untreated gas only) or through butyl XX synthetic rubber tubing which has a very low permeability to gas (Esco Rubber Co., London). Wherever possible, silicone tubing was replaced by butyl XX synthetic rubber tubing for other fermenter connections. The dissolved $\mathrm{O}_{2}$ concentration, $\mathrm{pH}$ and redox potential of the culture were monitored in situ with appropriate electrodes.

Batch culture experiments. The fermenter contained 101 of minimal medium supplemented with either $0.1 \mathrm{mM}$-L-methionine or with $0.13 \mathrm{~mm}$-L-methionine, $9 \mu \mathrm{M}$-thiamin, $0.11 \mathrm{~mm}$-L-lysine and $1 \mathrm{~mm}$-sodium

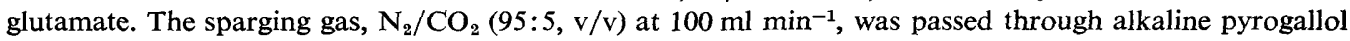
and reduced benzyl viologen before entering the fermenter.

All analyses were as described by Keevil et al. (1979). Each experiment was repeated once with an independently established continuous culture and essentially identical results were obtained (see Keevil et al., 1979). Batch cultures were also used for preliminary and control experiments to investigate the effect of traces of $\mathrm{O}_{2}$ in the sparging gas on 2-oxoglutarate dehydrogenase activity.

\section{RESULTS}

\section{Effect of glutamate on 2-oxoglutarate dehydrogenase synthesis}

Anaerobic batch cultures of $C$. freundii, sparged with $\mathrm{N}_{2} / \mathrm{CO}_{2}(95: 5, \mathrm{v} / \mathrm{v})$ which had been passed through alkaline pyrogallol and reduced benzyl viologen (and was therefore probably $100 \% \mathrm{~N}_{2}$ ), grew equally well in minimal medium supplemented with methionine alone or with methionine, lysine, thiamin and glutamate (Keevil et al., 1977b). Yield coefficients, fermentation balances, cytochrome concentrations and activities of 10 enzymes other than 2-oxoglutarate dehydrogenase were similar for both types of culture and confirmed the data reported previously (Keevil et al., 1979). In contrast, 2-oxoglutarate dehydrogenase was 50 times more active in the fully supplemented culture $-5.0 \mathrm{nmol}$ $\mathrm{NAD}^{+}$reduced $\mathrm{min}^{-1}$ (mg protein) ${ }^{-1}$ compared with $0.1 \mathrm{nmol} \mathrm{min}^{-1}$ (mg protein) ${ }^{-1}$ for the culture from which glutamate was omitted. Thus glutamate, or a metabolite of glutamate such as 2-oxoglutarate, is an inducer of 2-oxoglutarate dehydrogenase synthesis. 
Table 2. Enzyme activities in cell membrane and soluble protein fractions of $C$. freundii grown anaerobically and aerobically in a carbon-limited continuous culture

Units of enzyme activity are nmol $\mathrm{NAD}^{+}$reduced or NADH oxidized $\min ^{-1}$ (mg protein) ${ }^{-1}$ or nmol substrate converted $\min ^{-1}$ (mg protein) ${ }^{-1}$.

\begin{tabular}{lrrr} 
Enzyme & None & $\begin{array}{c}\text { Heated } \\
\text { copper }\end{array}$ & $\begin{array}{c}\text { Alkaline } \\
\text { pyrogallol } \\
+ \text { BV* }\end{array}$ \\
\cline { 2 - 4 } Alcohol dehydrogenase & 10 & 12 & 24 \\
Lactate dehydrogenase & 660 & 500 & 510 \\
Pyruvate dehydrogenase & 71 & 70 & 70 \\
Citrate synthase & 35 & 38 & 21 \\
Aconitate hydratase & 100 & 75 & 90 \\
Isocitrate dehydrogenase & 190 & 170 & 200 \\
2-Oxoglutarate dehydrogenase & 26 & 15 & $0 \cdot 2$ \\
Succinate dehydrogenase & 24 & 27 & 72 \\
Fumarate hydratase & 1440 & 1050 & 360 \\
Malate dehydrogenase & 5000 & 5300 & 5700 \\
NADH oxidase & 36 & 30 & 42 \\
\multicolumn{1}{c}{$*$ BV, Reduced benzyl viologen. } & &
\end{tabular}

\section{Effect of traces of oxygen on growth and fermentation products}

No supplements are required for $C$. freundii to grow anaerobically in minimal medium (Keevil et al., 1977b). In order to study the effects of low concentrations of oxygen in the absence of catabolite repression or regulatory effects of glutamate, bacteria were subsequently grown in a carbon-limited continuous culture in unsupplemented minimal medium.

No $\mathrm{O}_{2}$ was detected with the $\mathrm{O}_{2}$ electrode even when the culture was sparged with untreated $\mathrm{N}_{2} / \mathrm{CO}_{2}(95: 5, \mathrm{v} / \mathrm{v})$, but the redox potential decreased from $-255 \mathrm{mV}$ to $-262 \mathrm{mV}$ or to $-275 \mathrm{mV}$, respectively, when the heated copper column or the alkaline pyrogallol purgers were introduced into the line carrying the sparging gas (Table 1).

The decrease in the oxidation-reduction potential of the culture was accompanied by a decrease in the molar growth yield, but the yield was still greater than in previous continuous culture experiments with fully supplemented minimal medium (Table 1; Keevil et al., 1979). Furthermore, less glucose-carbon was metabolized to soluble fermentation products than in the previous experiments. More of the soluble products accumulated when the sparging gas was treated to remove the last traces of $\mathrm{O}_{2}$ than when it was untreated, and smaller quantities of volatile carbon compounds were produced. When the $\mathrm{O}_{2}$ purging systems were used, more formate, acetate, ethanol and succinate but less lactate, pyruvate, fumarate, malate, isocitrate and citrate accumulated. Less than $7 \%$ of the carbon in the culture supernatant remained unidentified by the gas-liquid chromatographic methods used.

\section{Enzyme activities and concentrations of cytochromes in cell-free extracts}

When the alkaline pyrogallol and reduced benzyl viologen were introduced into the gas line, alcohol dehydrogenase and succinate dehydrogenase (plus fumarate reductase) activities increased two- to threefold, fumarate hydratase activity decreased fourfold and 2-oxoglutarate dehydrogenase activity was almost undetectable (Table 2). Similar but smaller changes in the enzyme activities occurred when the sparging gas was passed through the heated copper column. NADH oxidase activity was low during each steady-state (Table 2). These data illustrate that changes in rates of enzyme synthesis are more readily correlated with the redox potential of a culture than with the dissolved oxygen concentration (Wimpenny \& Cole, 1967; Wimpenny, 1970). 
Table 3. Concentration of cytochromes in cell membrane and soluble protein fractions of $C$. freundii grown anaerobically in a carbon-limited continuous culture

Units of cytochrome concentration are pmol (mg protein) $)^{-1}$.

\begin{tabular}{|c|c|c|c|c|}
\hline \multirow[b]{2}{*}{ Cytochrome } & \multirow[b]{2}{*}{ Type of spectrum } & \multicolumn{3}{|c|}{ Inlet gas treatment } \\
\hline & & None & $\begin{array}{l}\text { Heated } \\
\text { copper }\end{array}$ & $\begin{array}{c}\text { Alkaline } \\
\text { pyrogallol } \\
+\mathrm{BV}^{*}\end{array}$ \\
\hline \multicolumn{5}{|l|}{$\begin{array}{l}\text { Membrane } \\
\text { fraction }\end{array}$} \\
\hline$o$ & Reduced plus $\mathrm{CO}$ against reduced & 180 & 160 & 300 \\
\hline $\begin{array}{l}a_{1} \\
b_{555}\end{array}$ & $\begin{array}{l}\text { Reduced against ferricyanide oxidized } \\
\text { Reduced against ferricyanide oxidized }\end{array}$ & $\begin{array}{r}18 \\
150\end{array}$ & $\begin{array}{l}\text { ND } \\
190\end{array}$ & $\begin{array}{l}\text { ND } \\
350\end{array}$ \\
\hline \multicolumn{5}{|l|}{$\begin{array}{l}\text { Soluble } \\
\text { fraction }\end{array}$} \\
\hline$o$ & Reduced plus $\mathrm{CO}$ against reduced & 75 & 70 & 70 \\
\hline$a_{1}$ & Reduced against ferricyanide oxidized & 18 & 31 & 39 \\
\hline$c_{552.5}$ & Reduced against ferricyanide oxidized & 190 & 185 & 245 \\
\hline
\end{tabular}

The predominant haemoproteins in membranes prepared from $C$. freundii from each steady state were cytochromes $o, a_{1}$ and $b_{555}$ (Table 3 ). The concentration of cytochrome $d$ was almost too low to be detected. When the sparging gas was passed through alkaline pyrogallol and reduced benzyl viologen, the concentration of the most abundant cytochrome oxidase, cytochrome $o$, increased, but cytochrome $a_{1}$ could no longer be detected. In contrast, the concentration of the soluble cytochromes $a_{1}$ and $c_{552.5}$ increased when traces of $\mathrm{O}_{2}$ were removed from the inlet gases. A soluble carbon monoxide-binding haemoprotein with an absorption maximum corresponding to cytochrome $o$ was also detected, but its concentration was not significantly affected by the presence or absence of residual $\mathrm{O}_{2}$ (Table 3).

Similar changes in enzyme activities and cytochrome concentrations were detected when the $\mathrm{N}_{2} / \mathrm{CO}_{2}$ sparging gas was replaced by 'White Spot' $\mathrm{N}_{2}$ : the changes were not, therefore, due to the removal of $\mathrm{CO}_{2}$ as the gas passed through alkaline pyrogallol and reduced benzyl viologen. Furthermore, the observed changes were reversible by sparging the fermenter with untreated 'White Spot' $\mathrm{N}_{2}$.

\section{DISCUSSION}

Amarasingham \& Davis (1965) proposed that acetate is an inducer of 2-oxoglutarate dehydrogenase synthesis in Escherichia coli. Dietrich \& Henning (1970) concluded that the syntheses of pyruvate and 2-oxoglutarate dehydrogenases are coordinately regulated by dihydrolipoyl dehydrogenase which is a common component of these enzyme complexes (but see Langley \& Guest, 1978). Neither of these regulatory mechanisms is likely to operate in $C$. freundii because there was no correlation between either the concentration of acetate or the pyruvate dehydrogenase activity and the 2-oxoglutarate dehydrogenase activity.

The data in Tables 1 to 3 clearly demonstrate that less than 20 p.p.m. $\mathrm{O}_{2}$ in a commercial compressed gas is sufficient to affect significantly the synthesis and incorporation of respiratory chain components into the cytoplasmic membrane. The unexpectedly high activities of 2-oxoglutarate dehydrogenase detected previously in anaerobic cultures of C. freundii can now be ascribed to two factors which independently induced the synthesis of this enzyme; these were the supplementation of the minimal growth medium with 
glutamate, and the failure to remove the last traces of $\mathrm{O}_{2}$ from the gas passed into the cultures.

The potential tricarboxylic acid cycle activity is therefore regulated both by $\mathrm{O}_{2}$ and glutamate, which induce 2-oxoglutarate dehydrogenase synthesis, and by catabolite repression of succinate dehydrogenase synthesis. The relative importance of these regulatory mechanisms in determining cellular physiology will depend on the environmental conditions: regulation by $\mathrm{O}_{2}$ will be the major factor only in the most fastidiously anaerobic niches such as the rumen or in lower layers of soil or mud. Conversely, catabolite repression of succinate dehydrogenase synthesis will be the dominant factor when $C$. freundii is growing as a contaminant of a brewery fermentation (Keevil et al., 1979). Although variations of 12- to 240-fold in the activities of succinate dehydrogenase and 2-oxoglutarate dehydrogenase were detected with relatively small changes in the growth conditions, these physiological changes were accompanied by only minor alterations in the products of bacterial metabolism or in the yield coefficient. This suggests that although catabolic and respiratory enzymes are synthesized at rates sufficient to cope with a sudden exposure to an excess of a terminal electron acceptor, the flux of metabolites through the tricarboxylic acid cycle is primarily determined by the supply of a reducible electron acceptor rather than by rates of enzyme synthesis.

The work was supported by funds from The Brewers' Society to C.W.K. and J.S.H.

\section{REFERENCES}

Amarasingham, C. R. \& Davis, B. D. (1965). Regulation of $\alpha$-ketoglutarate dehydrogenase formation in Escherichia coli K12. Journal of Biological Chemistry 240, 3664-3668.

Dietrich, J. \& Henning, U. (1970). Pyruvate dehydrogenase complex synthesis in Escherichia coli. European Journal of Biochemistry 14, 258-269.

Hempfling, W. P. \& Mainzer, S. E. (1975). Effects of varying the carbon source limiting growth yield and maintenance characteristics of Escherichia coli in continuous culture. Journal of Bacteriology 123, 1076-1087.

Keevil, C. W., Hough, J. S. \& Cole, J. A. (1977a). The effects of glucose, succinate and cyclic adenosine $3^{\prime}, 5^{\prime}$-monophosphate on the synthesis of tricarboxylic acid cycle enzymes and respiratory components in Citrobacter freundii. FEMS Microbiology Letters 1, 329-331.

KeEvn, C. W., Hough, J. S. \& Cole, J. A. (1977b). Prototrophic growth of Citrobacter freundii and the biochemical basis for its apparent growth requirements in aerated media. Journal of General Microbiology 98, 273-276.

Keevil, C. W., Hough, J. S. \& Cole, J. A. (1979). Regulation of respiratory and fermentative modes of growth of Citrobacter freundii by oxygen, nitrate and glucose. Journal of General Microbiology 113, 83-95.

LANGLEY, D. \& Guest, J. R. (1978). Biochemical genetics of the $\alpha$-keto acid dehydrogenase complexes of Escherichia coli K12: genetic characterization and regulatory properties of deletion mutants. Journal of General Microbiology 106, 103-117.

WIMPENNY, J. W. T. (1970). The effect of $E_{\mathrm{h}}$ (redox potential) on regulatory processes in facultative anaerobes. Biotechnology and Bioengineering 11, 623-629.

Wimpenny, J. W. T. \& Cole, J. A. (1967). The regulation of metabolism in facultative anaerobes. III. The effect of nitrate. Biochimica et biophysica acta 148, 233-242. 